\title{
O Partido Comunista Chileno e Aliança de Intelectuais: Uma Frente pela democracia (1937-1940)
}

\section{The Chilean Communist Party and the Aliance of Intellectuals:}

A Front for democracy (1937-1940)

\author{
Ana Amelia M. C. Melo* 1
}

Resumo: O objetivo deste artigo é o de examinar as relações entre o Partido Comunista Chileno e a Alianza de Intelectuales de Chile para la Defensa de la Cultura (AICH). A delimitação temporal é estabelecida pela data de fundação da entidade (1937) e finaliza com último número da revista, Aurora de Chile apresentado como órgão oficial da AICH. Buscamos identificar os intelectuais que formavam o grupo, as atividades que desenvolvem e em que medida seguem as diretrizes comunistas, sobretudo relativas a formação da Frente Popular e defesa da bandeira antifascista. Consideramos que a influência da Comintern foi inegável, entretanto isso não significou um controle absoluto sobre este variado grupo de intelectuais da AICH.

Palavras-Chave: Comunistas, Intelectuais, Antifascismo, Frente Popular

\begin{abstract}
The purpose of this article is to examine the relations between the Chilean Communist Party and the Alliance of Intellectuals of Chile for the Defense of Culture $(\mathrm{AICH})$. The temporal delimitation is established by the foundation date of the entity (1937) and ends with the last issue of the magazine, Aurora de Chile presented as the official body of the AICH. We seek to identify the intellectuals who formed the group, the activities they develop and the extent to which they follow the communist guidelines, especially regarding the formation of the Popular Front and the defense of the antifascist struggle. We believe that Comintern's influence was undeniable, but this did not mean absolute control over this diverse group of Aichi intellectuals.
\end{abstract}

Keywords: Communists, intellectuals, anti-fascism, Popular Front

Recibido: 21 marzo 2019 Aceptado: 22 abril 2019

*Brasileira, Professora Associada do Programa de Pós-graduação em História Social, Departamento de História da Universidade Federal do Ceará (UFC). Este artigo é fruto de pesquisa de Pós-Doutorado realizado na Universidade de Santiago de Chile em 2017. E-mail: anameliademelo@gmail.com 


\section{Comunistas e intelectuais}

As relações entre os comunistas e intelectuais tem sido marcadas, ao longo do século XX, por uma grande diversidade. As diferenças residem nas múltiplas situações históricas de cada sociedade onde está presente a organização comunista e se encontra associada ao lugar e papel que cada Partido Comunista desempenha na vida política do país, assim como o lugar e status dos intelectuais no interior da sociedade. ${ }^{2}$ Não há dúvidas, entretanto, quanto a importância que adquiriram os temas culturais na URSS e, consequentemente, os vínculos entre o partido e trabalhadores da cultura. Nos anos 1920, quando foram criadas duas instituições centrais encarregadas de desenvolver as relações culturais soviéticas: a VOKS, sigla em russo da Sociedade para as Relações Culturais com o Exterior, concebida em 1925 pelo Comitê Central do Partido Comunista da União Soviética com o objetivo de promover interações entre as instituições públicas, acadêmicos e trabalhadores da cultura dos países ocidentais, e a Associação internacional de Escritores Revolucionários (MORP) que tinha o propósito de promover a cultura soviética disponibilizando material traduzido para a rede de imprensa comunistas e simpatizantes. ${ }^{3}$

No entanto, apesar do interesse, a organização partidária desconfiava dos intelectuais por sua "extração de classe" pequeno burguesa. Somente a partir das mudanças desenvolvidas nos anos 1930, quando a Comintern adota uma nova perspectiva baseada na necessidade de unidade e alianças políticas é possível identificar uma adesão ampla de intelectuais aos Partido Comunistas em diversos países, sobretudo engajados na bandeira do antifascismo.

No Chile, a relação entre intelectuais e o Partido Comunista pode ser identificada a partir da formação da Aliança de Intelectuais para a Defesa da Cultura (AICH), entidade que se funda numa cerimônia realizada no dia sete de novembro de 1937 no Salão de Honra da Universidade do Chile, em Santiago. O evento reuniria em torno de 150 intelectuais entre eles prestigiosos escritores e homens e mulheres de reconhecida atividade cultural no país. Nesse momento era lançada o manifesto em defesa da Espanha, da liberdade e da cultura. Estiveram presentes na solenidade além de Pablo Neruda, Presidente da AICH, o poeta argentino Raúl González Tuñon, o escritor peruano Luis Alberto Sanchez, o poeta chileno Gerardo Seguel, Julio Barrenechea, Gabriel Amunátegui, diretor de bibliotecas entre outros. A decisão sobre a organização de uma entidade formada por intelectuais antifascista foi tomada nesse mesmo ano no II Encuentro de Escritores en Defensa de la Cultura de Valência, no qual Pablo Neruda esteve presente e assumiu o compromisso de criar a Aliança no Chile.

Nacionalmente o contexto é de acirrada tensão no último ano do governo de Arturo Alessandri. No poder desde 1933 Alessandri primou por uma postura autoritária, perseguindo lideranças sindicais, fechando jornais e impondo com a ajuda de um congresso conservador, leis de exceção. Durante esse segundo mandato foram frequentes os usos de prerrogativas especiais e cassação de direitos constitucionais. Em fevereiro de 1937, foi promulgada a Lei no 6.026 conhecida como Ley de Seguridad Interior del Estado, institucionalizando práticas de vigilância, prisão e proibição de reuniões assim como de circulação de impressos ${ }^{4}$. Com a lei e, inclusive, o rechaço de inscrição no Registro Eleitoral, o Partido Comunista foi mantido na ilegalidade até 1938 com a vitória de novo presidente Aguirre Cerda.

A formação da Aliança no Chile pode ser pensada em estreita relação com a constituição da Frente Popular no país, desde fevereiro de 1936. Esta, por sua vez, se bem estava relacionada à estratégia do

\footnotetext{
${ }^{2}$ Frédérique Matonti, "Les intellectuels et le Parti: le cas français", M. Dreyfus, B. Groppo (eds), Les siècles des communismes, Éditions de L Atelier/Edition ouvrières, Paris, 2004.

${ }^{3}$ Adriana Petra, Intelectuales y cultura comunista: itinerarios, problemas e debates en la Argentina de posguerra. FDE, 2017, p. 46. Natalia Kharitonova, La Internacional Comunista, la MORP y el movimiento de artistas revolucionarios españoles (1932-1934), IEE, Document, n. 37, 01/2005. http://www.uclouvain.be/cps/euro/documents/kharitonova37.pdf

${ }^{4}$ Elizabeth Lira e Brain Loveman, Poder Judicial y conflitos politicos (Chile: 1925-1958), Santiago, Universidad Alberto Hurtado/LOM. 2014, p. 291.
} 
comunismo internacional se constituiu a partir das dinâmicas políticas e sociais internas. ${ }^{5} \mathrm{~A}$ orientação política dos partidos comunistas que tomam a frente no processo de constituição de uma Frente Popular, a partir de 1935 foi de abandonar a linha política de "classe contra classe" e adotar uma política de unidade para combater o inimigo comum, o fascismo. Já em fevereiro de 1935 enviados da Comintern da URSS chegam ao Chile com a missão de apresentar mudanças de linha do Partido Comunista, propondo um amplo movimento de Frente Única. ${ }^{6}$

Entretanto, a peculiaridade da Frente Popular no Chile esteve associada ao importante papel desempenhado pelos partidos Radical e Socialista e a uma tradição política anterior de conformação de alianças ou blocos como o Block de Izquierdas (1934-35), Frente Único Socialista (1933), Frente Obrero de los Trabajadores Revolucionários (1932), Alianza Socialista Revolucionaria de Trabajadores (1932) Comite Revolucionario de Frente Unico Obrero (1931) ${ }^{7}$

A confluência dessas conjunturas de ameaça às liberdades políticas e civis, a formação da Frente Popular e a solidariedade no conflito espanhol vão definir o perfil da Aliança. Elas circunscreveram a pauta das discussões assim como a atuação da AICH, desde sua fundação até 1940 um ano após o governo chileno garantir asilo político aos republicanos espanhóis, assegurando a saída da Europa e translado a Valparaíso de aproximadamente 2 mil pessoas 8 .

Os registros encontrados até o momento, apontam para a existência da AICH até 1954. ${ }^{9}$ Podemos afirmar nesse sentido, que a Aliança ao longo desses dezessete anos, passou por diversas fases relacionadas a vida política do país. O primeiro período vai dos anos 1937 a 1940, ou seja, de sua fundação até a eleição nacional do presidente Aguirre Cerda e conformação da Frente Popular. Esse. É nesse momento que a AICH cria sua revista Aurora de $C_{b i l e}{ }^{10} \mathrm{e}$ os intelectuais se engajam intensamente na defesa dos republicanos espanhóis. Um segundo momento se inicia a partir de 1941, quando desaparece a revista Aurora de Chile e politicamente a Frente Popular sofre uma reestruturação pela crise interna entre os partidos apoiadores e morte prematura do presidente do Chile, Aguirre Cerda. A Aliança continua ativa, porém menos militante. Esta etapa pode ser delimitada até 1946 quando se dá a eleição de González Videla (1946-1952). De 1946 a 1954, o trabalho da AICH torna-se mais difícil. Esse período é marcado por um acirramento político maior, com a perseguição aos comunistas e, no interior do partido uma política de acossamento ideológico aos artistas e escritores que não aderiam estritamente ao realismo socialista $^{11}$. No caso específico do Chile estes anos foram muito particulares para o PC uma vez que, pela primeira vez não apenas o partido ajudou a eleger o presidente González Videla (1946-1952), como formou parte do seu gabinete, por uma breve temporada até abril de 1947 e foi em seguida, objeto de perseguição do governo Gonzalez Videla.

\footnotetext{
5 Pedro Milos, La formación del Frente Popular, 1936-1938. Santiago, Lom Ediciones, 2008, p. 28.

${ }^{6}$ Rolando Alvarez El Partido Comunista de Chile en la década de 1930: entre "clase contra clase" y el Frente Popular. Pacarina del Sur, n. 31, Santiago, 2017. Disponível em: <http://www.pacarinadelsur.com/home/ oleajes/1474-el-partido-comunista-dechile-en-la-decada-de-1930entre-clase-contra-clase-y-el-frente-popular>. Acessado em: 5/01/2019. p. 27.

7 Alberto Aggio, Frente Popular, radicalismo e Revolução Passiva no Chile, São Paulo, Annablume, FAPESP, 1999.

${ }^{8}$ No dia 4 de agosto de 1939 partiu do porto de Poullac, na Franca, o cargueiro Winnipeg com 2.200 refugiados espanhóis que chegaram ao porto de Valparaíso em 3 de setembro de 1939. A organização e traslado ficou a cargo de Pablo Neruda, designado pelo governo chileno como Consul. Ver: Memoriachilena.gob.cl. Consulta 04/02/2019.

${ }^{9}$ A última menção encontrada até o momento, onde se fala da existência da AICH aparece em carta escrita por Mireya Lafuente a Gabriela Mistral, na qual a primeira fala de ser presidente da Aliança de Intelectuais. A carta é de janeiro de 1954.

10 Segundo seus editores tratava-se de defender o espírito de "independência" e "liberdade" de 1812. O título da revista se inspira no primeiro jornal homônimo de chile editado por frei Camilo Henríquez (1769-1825), no processo de independência das colônias espanholas.

11 O realismo socialista é consagrado oficialmente no Congresso de Escritores de 1934 realizado em Moscou. Nele estava presente Andrei Zdanov (1896-1948) quem se tornará uma das figuras mais conhecidas e defensoras dessa perspectiva da arte e da literatura que obedecia às diretrizes estritas da política de Estado de Stalin. Ver: Victorio Strada. "Do realismo socialista ao Zdhanovismo”, Erick J Hobsbawm, História do marxismo, vol. 9. Rio de Janeiro, Paz e Terra,1985, p. 141.
} 
Buscamos neste estudo demonstrar as estreitas ligações da AICH com o Partido Comunista, sobretudo através da adoção de um "antifascismo comunista" ${ }^{12}$. Neste momento analisaremos o primeiro período da AICH, ou seja, desde sua fundação até 1940, quando deixam de editar a revista Aurora de Chile. Como dito, apesar de haver registro da continuidade da Aliança, as fontes não permitem até o momento, identificar com rigor suas formas de atuação, a dinâmica de seu funcionamento e o debate de ideias. A hipótese central aqui defendida é a de que a AICH foi um braço do Partido Comunista Chileno e representou o projeto de Frente Popular, utilizando figuras exponenciais e de prestígio do mundo da cultura no Chile para ampliar sua inserção na sociedade e ganhar adesões. É necessário fazer a ressalva de que estes intelectuais não foram um grupo monolítico ou estático, tampouco foram "usados" como massa de manobras do partido. Devem ser entendidos como agentes portadores de um sentido crítico que acreditaram na possibilidade de transformação do país e no seu papel e contribuição nesse processo. Compartem de uma cultura política comunista ${ }^{13}$ de longa data e são sujeitos ativos da constante reelaboração dessa cultura comunista. Aderimos à perspectiva de alguns historiadores quando destacam a necessidade de matizar o resultado automático das diretrizes da Comintern. ${ }^{14} \mathrm{~A}$ indisciplina dos militantes e a própria dinâmica da política nacional, ao fim e ao cabo, era o que decidia os rumos nacionais do partido e tornava realidade as diretrizes da Internacional Comunista.

\section{A Aliança de Intelectuais do Chile}

Os fundadores da $\mathrm{AICH}$, o que era denominado Primeiro Diretório, era formado por Pablo Neruda, seu primeiro presidente, membro também do Comitê Central da Associação Internacional de Escritores; Alberto Romero (1896-1981), Gerardo Seguel (1902-1950), Luis E. Délano (1907-1985), H. Diaz Casanueva (1906-1992) e Juan Negro (1906-1979). Estes seis escritores eram neste momento, figuras importantes da vida cultural do Chile, bastante conhecidos do público em geral, escreviam em jornais e revistas além de participarem em atividades culturais diversas. Alberto Romero nos anos 1930 já havia escrito alguns livros de literatura muito bem recebido pela crítica além de escrever na revista ZigZag e nos jornais Últimas Noticias e Diário Ilustrado. ${ }^{15}$ Nesse período, entre 1938-1939 foi também diretor da Sociedade Chilena de Escritores (SECH). ${ }^{16}$

Por sua vez o escritor Gerardo Seguel também era considerado um destacado intelectual, com várias publicações de livros de poesias. ${ }^{17}$ Gerardo Seguel manteve sua atividade de professor e sua militância política, atundo como dirigente da Associação de Professores, foi duramente perseguido até ser exonerado nos anos 1930, quando sai exilado do país percorrendo Argentina, Uruguai e Brasil. Segundo as memórias de Delano, Seguel ingressou no Partido Comunista em1931 quando volta da Espanha. ${ }^{18}$

\footnotetext{
12 Bruno Groppo, El antifascismo en la cultura política comunista, Anuario IESH 19 (2004), p.748.

${ }^{13}$ Sobre Cultura Política ver: Serge Berstein, A cultura política, Jean-Pierre Rioux e Jean-Francois Sirinelli (Org.) Por uma História Cultural, Lisboa, Estampa, 1998. Sobre Cultura Comunista ver: David-Fox, Michael (2017). "Communism and Intellectuals", Pons, Silvio, World Revolution and Socialism in One Country, 1917-1941, Cambridge University Press; Dreyfus, M.; Groppo, B. Les siècles des communismes, Éditions de L Atelier/Edition ouvrières, Paris, 2004.

14 Ver: Rolando Alvarez, op. cit., p. 10; Acessado em: 5/01/2019.

${ }^{15}$ La viuva del conventillo publicada em 1930, obteve grande sucesso e aprovação da crítica. Também publicou Memórias de un amargado (1918), Soliloquio de un hombre extraviado (1925), Un infeliz (1927), La tragédia de Miguel Orožco (1929), etc.

16 Ana Gálvez Comandin. De lacra social a proletária urbana. La novela social y el imaginário de la prostitución urbana em Chile: 1902-1940. (tesis de Maestria em História), Universidad de Chile, 2011.

17 Sintonía de la Fiesta (1923), Hombre de Otoño (1924), Dos campanários a la orilla del cielo (1927) entre outros.

18 Marino Muñoz Lagos. El poeta Gerardo Seguel, in: La Prensa Austral, 19 de junio de 1997, p. 2. http://www.bibliotecanacionaldigital.cl/bnd/628/w3-article-289297.html. Visto em 03/01/2019. Gerardo Seguel é mencionado em documentação sobre órgãos de imprensa do Partido. Nela faz-se referência ao jorna Frente Popular e apontam o escritor como "camarada militante" que faz parte da Redação desse diário também registrado como órgão de imprensa do
} 
Enrique Délano foi igualmente militante comunista, poeta e escritor fecundo, aclamado pela crítica. ${ }^{19}$ Nos anos seguintes desenvolve uma intensa atividade jornalística, escrevendo no jornal $E l$ Mercurio, nas revistas Zig-Zag e Écran. A partir de 1934 passa a ser correspondente estrangeiro para El Mercurio na Europa até 1937.

H. Diaz Casanueva, a semelhança de Gerardo Seguel, inicia sua carreira como professor. ${ }^{20}$ Como professor tem uma ativa vida sindical e militante sendo forçado ao exilio em $1928 \mathrm{com}$ a ditadura de Ibañez del Campo, que vigorou no país entre 1927-1931. Juan Negro fez igualmente parte desta geração de escritores e militantes. ${ }^{21}$ Era poeta e ativo participante dos movimentos literários no Chile. Em 1949 trabalhou na Direção de Bibliotecas, Arquivos y Museos de Chile. Desde 1934 publica diversos livros de poesia e crônicas. Foi tesoureiro da AICH.

A figura central do grupo neste momento era Pablo Neruda. Havia pouco retornara da Espanha onde atuava como cônsul chileno. Nesses anos o poeta viveu intensamente a experiencia da Frente Popular na Espanha e o drama da Guerra Civil (1936-1939), marcando sua poesia e escrita e delineando uma posição política atuante em defesa dos republicanos. Se seu compromisso político já era antigo, desde os tempos da revista Claridad e de sua aproximação aos anarquistas nos anos 1920, como aponta Adriane Vidal, este compromisso aprofunda-se com a situação da Espanha. ${ }^{22}$

Podemos afirmar que o seu envolvimento com a Espanha desde 1934, quando chegou a Barcelona, e o texto "Sobre una poesía sin pureza", marcaram o início de uma grande mudança na poesia nerudiana. $\mathrm{E}$ os acontecimentos relacionados à guerra civil aprofundaram esta convicção, despertando de vez o compromisso político-social no poeta. ${ }^{23}$

No calor da guerra escreveria España en el Corazón, bimno a las glorias del pueblo onde sua escrita definitivamente apresenta um teor de luta e defesa dos oprimidos. A literatura passa a ser interpretada pelo poeta, a partir da dimensão histórica e social, no qual o escritor deve assumir uma posição clara contra toda injustiça. Segundo suas próprias declarações no livro de memórias Confesso que Vivi, a Guerra de Espanha mudou sua poesia, sobretudo desde a morte de seu amigo, o poeta Federico Garcia Lorca. ${ }^{24}$ A Guerra de Espanha fixa seu lugar político. Foi a partir do convívio com as atrocidades da guerra, com a morte de amigos, com o drama dos republicanos, com o avanço do fascismo que Neruda torna-se comunista por convicção. "Aunque el carnet militante lo recibí mucho más tarde en Chile, cuando ingresé oficialmente al partido, creo haberme definido ante mí mismo como un comunista durante la guerra de España. Muchas cosas contribuyeron a mi profunda convicción."25

A identificação com os comunistas dava-se sobretudo através da mobilização em solidariedade aos republicanos espanhóis. As declarações de Neruda sobre o fato de ser ou não comunista neste período são contraditórias. Em entrevista à revista Ercilla em 1937 negou ser um comunista. Para ele tratava-se de ser um escritor livre, defensor da cultura, da liberdade revelando-se sobretudo como um antifascista. ${ }^{26}$. Deve-se ressaltar que, no contexto desta entrevista, era importante reafirmar a necessidade

Partido Comunista de Chile. Olga Ulianova, "Listado de publicaciones periódicas del PCCH elaborado por Raúl Barra Silva." 16/01/1938. In: Chile en los archivos soviéticos (1922-1991. Tomo 3: Komintern y Chile 1935-1941. Santiago de Chile: DIBAM, Centro de Investigaciones Diego Barros Arana.2017, p. 409.Ver também: Enrique Delano, Aprendiz de Escritor. Santiago, Editorial Pluma y Pincel, 1994, p. 123.

19 Publica seu primeiro livro em 1926 El Pescador de Estrellas e em 1927 La niña de la prisión y otros cuentos.

20 Seu primeiro livro El aventurero de Saba (1926). Participa de Antologia de la Poesia Chilena Nueva (1935), organizada por Volodia Teiltelboim. Publica La Estatua de Sal (1947) entre outros.

${ }^{21}$ Seu nome era Juan Aguirre Hinojosa, foi poeta e contista. Publicou Mester de juglaría (1934); Mensaje de poesia (1936), Goces y muertes, poesía (1940) entre otros.

22 Adriane Vidal Costa, Pablo Neruda: uma poética engajada, Rio de Janeiro, E-Papers, 2007, p. 94.

23 Idem, p. 94.

24 Pablo Neruda. Confieso que he vivido: Memórias. Madrid, Seix Barral, 1980, p. 55.

25 Idem, p. 62

${ }^{26}$ Revista Ercilla, 12 nov. 1937. (Biblioteca Nacional de Chile) 
de formação da Frente Popular e de uma aliança ampla de luta contra o fascismo e, nesse sentido, não era apenas uma bandeira do comunismo. Em outra entrevista, nesse mesmo período, e suas posições nos debates sobre a militância de intelectuais, a perseguição aos chamados troskystas, Neruda dava demonstrações de seguir as orientações do partido.

Ao reunir esse conjunto expressivo de intelectuais a AICh pretendia demarcar seu objetivo, expresso muito claramente no que era sua "publicação oficial", conforme afirmações que apareciam na imprensa de Santiago. Em termos bem pontuais poderíamos expor dois objetivos centrais da aliança e que refletiam a conjuntura do momento. Por um lado, a defesa dos republicanos espanhóis, por outro e conjuntamente, a defesa da Frente Popular, seja esta a Frente de Espanha seja a Frente Popular no Chile. Mas do que uma entidade profissional de escritores e intelectuais, ela nasce como uma entidade política que representava os intelectuais.

Em uma nota publicada no jornal El Siglo, do Partido Comunista, no ano de 1940 o sentido político da AICH era insinuado quando o impresso comenta a impossibilidade, por motivos econômicos, de aparição da edição de Aurora de Chile, dedicada à Espanha. O jornal afirmava: "La edición dedicada al 14 de abril y, por lo tanto, al pueblo y a la cultura españolas, revelaba la voluntad de convertir lo que nació como un periódico de divulgación y agitación, en una revista de más intensa profundidad.” ${ }^{27}$. A Aliança também cumpria essa função de ser uma entidade de agitação política.

Mas foi no jornal Frente Popular vinculado ao Partido Comunista onde mais eram publicadas notícias sobre a formação da AICH. Antes do evento de criação no salão de Honra, o jornal informa sobre a convocatória para formação da Aliança. Tratava-se de uma reunião que se realizaria no dia cinco de novembro para discutir detalhes da entidade. Segundo dizia o jornal, a filiação bem como a participação nessa reunião estava aberta a quem tivesse interesse. Dando bastante destaque a formação da AICH o jornal aclamava as declarações dos jovens intelectuais, pronunciamentos de importantes escritores como as do poeta Vicente Huidobro que reafirmava a importância da organização dos intelectuais em uma entidade com o propósito de defesa da cultura. O jornal também divulgava as manifestações e opiniões do poeta Pablo Neruda e do escritor Alberto Romero. Dia sete de novembro aconteceria o lançamento da entidade, portanto nesses dias anteriores foi anunciado em diversas notícias o que seria a Aliança, seus propósitos, sua relevância e vinculações internacionais, demarcando a criação da AICH como parte de uma rede internacional relevante de luta contra o fascismo.

De fato a formação da AICH estava vinculada diretamente aos intelectuais antifascistas que realizaram durante a Guerra Civil Espanhola o II Encontro de Escritores em Defesa da Cultura reunidos de forma itinerante nas cidades de Valencia, Madrid e Paris. ${ }^{28}$ Este e outros congressos de intelectuais foram realizados durante os anos 1930 na Europa capitaneados em grande parte pela Internacional Comunista com o objetivo de construir as Frentes Populares contra o fascismo como têm demonstrado alguns estudos. ${ }^{29}$

A ênfase dada pelo jornal Frente Popular ao evento e a criação da Aliança está associada ao significado da entidade na conformação do movimento frentista. A Aliança constituía o braço mais visível e militante da cultura. A reunião de um conglomerado de artistas, escritores, professores, poetas, músicos prestigiados e conhecidos do público em geral dava força e visibilidade causa frentista no âmbito da sociedade como um todo, seguindo o exemplo de países como França e Espanha e a própria URSS. Eram nomes que frequentavam as páginas das revistas e jornais sendo apresentados como verdadeiras eminências da vida cultural do país. Dispor de seus nomes para a causa da Frente Popular significava ascender não apenas ao meio acadêmico, ao mundo do teatro e da música mas poder também utilizar a notoriedade de que dispunham para dar proeminência e legitimação entre o público que os seguia.

27 El Siglo, 31 agosto de 1940, p. 3

28 Matías Escalera Cordero. "Guerra, Pueblo y Cultura: Antonio Machado en el Congreso de Valencia (1937)”, ARBOR, Ciencia, Pensamiento y Cultura, clxxxv, 739, España, 2009, p.739.

29, Pascal Ory; Jean-François Sirinelli, Les intellectuels en France, de l'Affaire Dreyfus à nos jours, Paris, Armand Colin, 1986, p.93-112, Michel Winock, O século dos intelectuais, Rio de Janeiro, Bertrand Brasil, 2000. 
O estatuto da AICH era bastante explícito quanto a seus propósitos políticos. O documento em seu primeiro capítulo foi dividido em seis pontos:

1. Defender a cultura em todas suas formas contra as limitações que se opõem a sua expansão; 2. Combater toda tendência atentatória à cultura, à dignidade do homem e à evolução da sociedade; 3. Destruir os preconceitos raciais que se pretendem inculcar na consciência dos povos; 4. Estimular todas as campanhas em prol da paz, único estado em que a humanidade pode aspirar para seu desenvolvimento pleno; 5. Defender as formas democráticas de governo, por considerar que somente elas permitem o livre desenvolvimento da cultura e da pessoa humana; 6. Realizar obras de divulgação cultural entre as massas e intelectuais e propor por todos os meios a seu alcance o progresso cultural, social e económico da coletividade. ${ }^{30}$

O tom de manifesto busca combater as limitações à toda possibilidade de expressão cultural, só possível de ser exercida em um ambiente político de paz e democrático. Em cada um dos tópicos a perspectiva foi a da defesa da liberdade civil e política e da dignidade humana. A estratégia dessa luta partia da própria cultura, através da divulgação de obras literárias e artísticas, do debate, da discussão. De fato, a criação da revista Aurora de Chile e as diversas atividades que desenvolve procuram dar conta dessa perspectiva.

O documento citado coloca o problema da data de fundação da $\mathrm{AICH}$, que apresenta uma variação. O primeiro registro encontrado aparece no jornal Frente Popular que informava dias antes, da organização de intelectuais para a criação da seção chilena da Aliança de Intelectuais para a Defesa da Cultura. No dia cinco de novembro eram anunciadas as reuniões finais e publicadas as lista de filiações. ${ }^{31}$ As notícias informam da criação em sete de novembro de 1937. A mesma data aparece nove meses depois, na revista Aurora de Chile. O decreto de criação e o estatuto estão com data de 11/10/1943. Nesse mesmo decreto está anexada a ata de fundação da AICH onde se afirma ter sido esta criada em 24/9/1941. Podemos concluir que primeiro ela é fundada em ato público no Salão Nobre da Universidade de Chile e posteriormente, em 1941 se realiza a reunião de criação oficial com elaboração de ata. Finalmente o decreto que lhe dá forma jurídica somente sai em 1943. Enquanto isso a Aliança realiza suas atividades divulgada em jornais e revistas. Esse demorado processo nos faz crer que de fato a AICH começa a se preocupar com sua oficialização como entidade jurídica, somente após a vitória da Frente Popular e a proeminência que ela vai adquirir.

A Aliança tampouco manteve o mesmo Diretório nesta primeira fase. Pablo Neruda permaneceu como Presidente desde sua fundação até aproximadamente maio de 1939, quando a revista Aurora informa sobre as eleições de novo Diretório que passava a ser composto a partir de junho de 1939 pelo escritor e jornalista Roberto Aldunate (1898-1960) seu Presidente e mais cinco membros eleitos para a vice-presidência, além do Secretário, Geral Gerardo Seguel e Tesoureiro Juan Negro.32 Em 1940 a Presidência passa a ser exercida por Julio Barrenechea (1910-1979) poeta e deputado socialista.

Primeiramente vamos circunscrever o espaço social da Aliança, identificando seus membros através da formação do diretório responsável pelas decisões e atividades que desempenham, indicando as relações com o PC. Em seguida realizamos um exame das atividades que executam para, finalmente analisar o antifascismo comunista que prevalecia da entidade.

\section{Intelectuais em ação}

A AICH procurava disseminar o combate ao fascismo através de uma mobilização intensa que se traduzia na realização de comícios com os partidos políticos que formavam parte da Frente Popular,

${ }^{30}$ Estatuto de la Alianza de Intelectuales de Chile para la Defensa de la Cultura. Imprenta Cenit, Santiago de Chile, 1944.

31 Frente Popular, 5 de novembro de 1937.

32 Os cinco membros eran Alberto Romero, Julio Ortiz de Zarate, Victor Tevah, Maria Yan, Miguel Caradeux. 
reuniões menores em sua sede no centro de Santiago, atividades literárias e artísticas e conferências. No ano inaugural procuram concretizar várias atividades como de homenagens a escritores, algumas delas realizadas na Universidade do Chile e com a presença de literatos que falavam e examinavam a obra em destaque. Estas atividades além de servir de propaganda para a entidade, permitia introduzir uma arma poderosa de luta política aliada a questão da divulgação da cultura e da educação popular. O combate ao fascismo portava uma dimensão pedagógica de combate ao obscurantismo, fundamental na construção da Aliança, no engajamento de intelectuais e trabalhadores da cultura.

Por outro lado, o valor da cultura letrada na tradição comunista e de esquerda, de modo geral, outorgava ao combate pela cultura sentido de verdadeira cruzada na luta pela emancipação dos explorados. É com esse sentido que podemos entender as atividades de leituras e debates..$^{33}$ No final de 1937 ainda promovem no Teatro Municipal de Santigo um ato em favor da democracia espanhola com a presença de Pablo Neruda que fez uma apresentação lírica e do poeta do Partido Comunista da Argentina, Gonzalez Tuñon, quem falou sobre o povo espanhol e a guerra antifascista. No ano seguinte as atividades continuam intensas, procurando mecanismos para driblar a censura e autoritarismo do Governo Alessandri.

É incontestável nesse processo o caráter ameaçador que estas atividades representavam para setores conservadores da sociedade chilena, ciosos do controle da cultura. Chama atenção uma das atividades desenvolvidas pela AICH ainda no primeiro semestre de 1938, quando a aliança fez doações à Biblioteca Nacional de diversos exemplares de autores alemães proibidos pelo governo alemão. O gesto seria concretizado através de uma cerimônia oficial no estabelecimento, porém foi suspensa a atividade pelo poder executivo. O fato gerou manifestação no Congresso Nacional. Em ata da sessão Parlamentar de sete e treze de junho desse ano, encontramos registro do discurso do Deputado Rudecindo M. Ortega ${ }^{34}$ quem manifesta desconforto perante a aparente influência da embaixada da Alemanha na decisão de suspender a cerimonia. A câmara, sobretudo representada pelos deputados da Frente Popular, decide por um pedido ao governo, dos antecedentes que pautaram a decisão, exigindo explicações em prazo determinado. 35

Nesse ano de 1938 a campanha eleitoral concentra as atenções do país. A AICH dedica boa parte de seus esforços na campanha de Aguirre Cerda. A participação dá-se através da revista Aurora de Chile e na organização de eventos com a presença do candidato. A revista publicou números especiais enfatizando a crítica ao governo de Arturo Alessandri, visto como exemplo do fascismo nacional e o candidato que o representava Gustavo Ross; em oposição apresentava a defesa da democracia expressa pela Frente Popular. A edição de doze de outubro de 1938, as vésperas do pleito, é inteiramente dedicada ao candidato do Partido Radical. A foto de capa da publicação foi consagrada a Aguirre Cerda, cobrindo toda a frente da revista, apenas ladeada por uma coluna estreita contendo um texto de defesa do que chamavam o candidato da cultura. A edição apresentava além disso, três colunas assinadas cada uma delas por representantes dos Partidos Socialista, Radical e Comunista, ou seja, a Frente Popular. Já no segundo número do impresso a posição em defesa do candidato da Frente Popular é aberta com a chamada em letras garrafais: "Ante las elecciones presidenciales. Los intelectuales definen una actitud". ${ }^{36}$

Igualmente na celebração do Dia da Raça, em doze de outubro de 1938, a AICH organiza, com o apoio do Comitê Chileno de Ajuda a Espanha e pelo Patronato de Niños Españoles, o evento com o propósito de prestar solidariedade ao povo espanhol. No ato a presença do candidato Aguirre Cerda tinha valor simbólico, vinculando-o a solidariedade e aos valores da democracia, da defesa das liberdades e da cultura,

33 Como o exemplo da leitura realizada por Gerardo Seguel de artigo publicado na Revista Atenea sobre o poeta Carlos Pezoa Veliz, ou a Feira do Livro organizada com a Sociedade de Escritores de Chile, durante o final de dezembro de 1937 no centro de Santiago. Aurora de Chile, 1/8/1937.

34 O deputado Rudecindo Ortega com a eleição de Aguirre Cerda, em 1938, é nomeado seu ministro da Educação.

35 Ata Sesión Parlamentar, 7 de junio 1938 e 13 de junio 1938. Congreso Nacional.

36 Aurora de Chile, 17/8/1938, p. 8. 
acompanhado por consagrados intelectuais e militantes da Frente Popular como Pablo Neruda, o decano da Faculdade de Filosofia e Letras da Universidad de Chile e membro da AICH e militante do Partido Radical Luis Galdames, o deputado Socialista Manuel Eduardo Hubner, o chefe da Juventude Comunista Ricardo Fonseca, o líder Radical Santiago Labarca, a Secretária do Movimento de Emancipação das Mulheres do Chile Elena Cafarena entre outros. ${ }^{37}$ Estas organizações não agrupavam um número grande de pessoas, como nos aponta o historiador Rolando Alvarez, porém contavam com uma forte influência de comunistas, dando ao partido capacidade de atuação através da formação de uma rede de militantes que tinham possibilidade de diálogo com ampliados setores da sociedade. Evento semelhante, foi realizado na mesma data comemorativa de doze de outubro do ano anterior e contou com 60 mil assistentes. ${ }^{38}$

O ano de 1939 foi pautado por muitas atividades, desta vez expressando compromisso com o governo eleito. Uma das novidades que pode indicar a influência e crescimento da Aliança foi a criação de um programa na Radio del Pacífico. Segundo foi informado nas páginas de Aurora de Chile, no domingo 22 de janeiro se iniciou a transmissão de programa Cultural. Falaram ao microfone Pablo Neruda, Arturo Paredes, Gustavo Vila e Jorge Rubén Morales. As ações de difusão cultural, debates e homenagens tem continuidade no ano de 1939 e atos de solidariedade à Espanha e também nesse ano, aos atingidos pelo terremoto de Chillan em 24 de janeiro de 1939, que pela magnitude deixou milhares de vítimas e a cidade assolada pela destruição.

Nesse mesmo ano um dos membros da Aliança, Luis Galdames é nomeado pelo governo como Diretor Geral de Educação Primária, informação difundida pela revista Aurora. Igualmente a publicação aponta que com o governo da Frente Popular, a AICH desenvolveu iniciativas como apresentação do projeto de criação de uma Direção Geral ou Subsecretaria que organizasse e centralizasse todas as atividades culturais não escolares, sob a direção do Ministério de Educacao Pública. A proposta foi acolhida pelo ministro Rudecindo Ortega. ${ }^{39}$

Uma das notícias que maior destaque teve em Aurora de Chile nesse ano de 1939 foi a questão dos refugiados espanhóis. A AICH participa desde um princípio procurando organizar atividades de solidariedade e arrecadar ajuda material. Com a vitória de Aguirre Cerda Neruda foi nomeado Consul Delegado para a emigração espanhola em Paris. Em marco de 1939 a França toma conhecimento da disposição do Chile em receber os exilados. Com a ajuda do SERE (Servicio de Emigración de Refugiados Españoles), do CCHARE (Comité Chileno de Ayuda a los Refugiados Españoles) e com apoio da AICH conseguiu-se apoio financeiro para realizar o transporte e recepção dos refugiados que chegaram em Valparaíso no barco Winnipeg. ${ }^{40}$ A nomeação de Pablo Neruda é saudada pelo Secretário Geral do Partido Comunista Carlos Contreras Labarca. A notícia é anuncia em letras garrafais em Aurora de Chile. Numa solenidade "grandiosa" no teatro Caupolican Contreras afirmou:

Tengo el gran placer de comunicar a ustedes que un diplomático chileno -más que eso, un poeta, Pablo Neruda, que tal cantidad de belleza ha dado con su poesía al pueblo y que sabe prestigiar ante el mundo el nombre de su patria- ha sido enviado a Europa por el Gobierno del señor Aguirre Cerda y va ya en camino hacia Francia, con la bandera del Frente Popular en sus manos y con el bello bagaje de su poesía, a llevar, en nombre de Chile, una palabra de esperanza y la protección del Gobierno de nuestro país a los millares de refugiados españoles arrojados de su patria por el fascismo internacional. ${ }^{41}$

\footnotetext{
37 Aurora de Chile, 3/12/1938.

38 Alvarez. Op. Cit., p. 37.

39 Aurora de Chile, 6/4/1939

${ }^{40}$ Maria Victoria Guasch. Reconstrucción identitaria en el exilio político: los refugiados de la guerra civil española en Cbile, Universidad Academia de Humanismo Cristiano, Escuela de Historia (Tesis de Grado), Santiago, 2011, p. 24.

${ }^{41}$ Aurora de Chile, 6/4/1939.
} 
A chegada dos Espanhóis foi anunciada e recebida pela Aliança que, como era de se esperar, publicou várias homenagens aos refugiados que desembarcaram em Valparaíso em setembro de 1939. Nesses primeiros anos da Frente Popular, a Aliança proporciona ao governo seu respaldo e legitimidade garantidos pelas prestigiadas figuras que dela faziam parte. A AICH junto com a Sociedade de Escritores reuniu-se com o presidente, em maio de 1939, para apresentar um plano de ação cultural e na ocasião pediu apoio ao governo para o projeto de criação do Departamento de Propaganda e Cultura Operária e para a organização da Imprensa do Estado. ${ }^{42}$. Em 25 de outubro, celebrando um ano da eleição de Aguirre Cerda, a revista publicou uma edição especial comemorativa, na qual apresentava matéria de capa inteira, com o desenho de um punho erguido e a chamada "Gobiernos de centro, no! Solamente gobierno del pueblo y para el pueblo, gobierno del Frente Popular!" 43 Na edição de 30 de novembro desse ano, edita um número também comemorativo dos dois anos de existência da AICH reafirmando enfaticamente seu compromisso com a Frente Popular.

Em 1940 a revista apenas publica dois números. Um referente a janeiro e outro a dezembro desse ano. As informações sobre as atividades da Aliança passam a ser divulgadas sobretudo no jornal El Siglo, que além de difundir eventos culturais, conferências, lançamento de livros, etc, publicava artigos escritos por seus mais atuantes membros e que eram vinculados ao Partido, como Ruben Azocar, Diego Muñoz, Gerardo Seguel.

\section{Antifascismo Comunista na AICH}

Foi precisamente o antifascismo a pedra de toque que possibilitou a reunião e formação da Aliança no Chile sob a liderança do Partido Comunista. Como nos fala o historiador francês Bruno Groppo, o antifascismo mais do que um movimento político estruturado dos anos 1930-40, fez parte de uma sensibilidade política compartilhada entre intelectuais, militantes, homens e mulheres preocupados com o assenso do nazismo e fascismo desses anos. ${ }^{44}$

Inicialmente é preciso esclarecer a definição de antifascismo aqui adotada. Não é ele visto exclusivamente como um fenômeno italiano de reação ao fascismo, das décadas de 1920-30, mas como um fenômeno internacional amplo e diverso, conforme apontam alguns autores. ${ }^{45}$ Por outro lado, também deve ser diferenciado entre o fascismo que surge antes da guerra e o que surge após o fim da Segunda Guerra. ${ }^{46}$

Entendemos, portanto, o antifascismo como esse movimento de configurações variadas, de caráter internacional. Como um fenômeno complexo de resistência que engloba uma sensibilidade política e que marcou a cultura política de uma geração de intelectuais em todo o mundo. Não foi menor o fato de que em diversos países da América Latina importantes escritores e intelectuais assumissem essa bandeira e organizassem associações de luta antifascista e a partir delas realizassem encontros, congressos, marchas, editassem jornais, manifestos públicos e inumeráveis outras atividades com o fim de denunciar e resistir às diversas formas do fascismo no continente americano. Tampouco foi unicamente propriedade de um partido. Podemos considerar, dessa forma, o seu caráter como relativamente autônomo, a saber, que era transversal aos partidos, movimentos e correntes políticas progressistas.

\footnotetext{
42 Aurora de Chile, 6/5/1939.

43 Aurora de Chile, 25/10/1939.

${ }_{44}$ Bruno Groppo. "El antifascismo en la cultura política comunista", Anuario IESH, 19, (2004).

45 Bruno Groppo (2004). "Fascismes, antifascismes et communismes", M. Dreyfus; B. Groppo. Les siècles des communismes, Éditions de L Atelier/Edition Ouvrières, Paris, 2004; Erick J. Hobsbawm. "Os intelectuais e o antifascismo", História do marxismo, vol. 9, Rio de Janeiro, Paz e Terra, 1985; Norberto Bobbio, Nivola Matteucci e Gianfranco Pasquino. Dicionário de Política, UNB, 1998.

46 Groppo, op. cit, p. 28.
} 
O antifascismo não foi um mito construído pela Comintern para obscurecer os crimes cometidos pela Stalinismo. ${ }^{47}$ Existiram outras correntes do antifascismo presentes entre anarquistas, trotskistas, socialistas ou sociais-democratas. Bruno Groppo nos elenca numerosas acepções que remontam à própria experiência histórica do antifascismo, caracterizado por uma variedade de ideias e movimentos. Desde a vitória de Hitler em 1933, o antifascismo tornou-se um problema central, uma realidade que ameaçava e crescia pela Europa. Deixou de ser uma questão meramente política para transformar-se, na perspectiva dos atores históricos desse período, numa ameaça à civilização. $\mathrm{O}$ fascismo não apenas desprezava o marxismo como todo tipo de liberalismo.

Por outra parte, como aponta Hobsbawn apesar de não existir na América Latina uma ameaça concreta de fascismo semelhante a Itália ou Alemanha, as simpatias da direita tradicional com o fascismo europeu e dos movimentos de extrema direita, despertaram na esquerda um sentimento de identificação com o antifascismo. Fundamental nesse processo foi a Guerra Civil Espanhola especialmente no México, Chile e Cuba. ${ }^{48}$

No caso aqui estudado, a AICH estabelecia o vínculo com a luta internacional contra o fascismo, ressaltando o fenômeno desde o primeiro número da revista Aurora de Chile. Na sua perspectiva não se tratava apenas de uma luta doméstica ou menor, mais essencial, inserida no movimento mundial em defesa dos princípios democrático. Tampouco era apenas uma luta de comunistas, mas uma luta de democratas em defesa dos princípios gerais de liberdade, respeito e dignidade da humanidade. Estes foram de fato os princípios norteadores da luta antifascista, em seu sentido amplo e que incorporou variados grupos políticos.

Aurora de Chile apresentava no lançamento, sua posição contra o fascismo e o apelo a unidade:

La presencia del fascismo en el campo internacional, su ataque directo a las bases de la cultura - la libertad, la dignidad humana, la independencia de las naciones y la persona mismo de los intelectuales - ha hecho surgir un mandato de unidad para todos los trabajadores del espíritu, en el mundo entero. ${ }^{49}$

Nesse contexto destacamos o fato, seguindo as pistas apresentadas por Gropp, de que a Comintern possuía uma estratégia oficial com relação ao antifascismo, ou seja, a Comintern produziu um discurso e uma doutrina oficial e buscou impô-la aos demais partidos comunistas. A doutrina variou ao longo do tempo, podendo ser identificadas duas interpretações do antifascismo bastante marcantes: uma relativa aos anos 1920 e que não estabelecia diferenças fundamentais entre o fascismo e as democracias liberais ou chamadas burguesas; outra que adquire relevo a partir de 1934 e 1935 e tomou como exemplo a vitória nazista na Alemanha. Esse antifascismo estabelecia uma diferença entre democracia liberal e fascismo e apelava para a defesa da primeira.

Le fascisme n'etait plus considéré comme l'expression du capitalism en tant que tel, mais selon la célèbre formule de Dimitrov au VII Congrès du Komintern en 1935, como 1 emanation des elements les plus réactionaire, les plus chauvins, les plus imperialistes du capital financiere. ${ }^{50}$

Foi esse tipo de estratégia que possibilitou a construção de uma aliança defensiva com setores da burguesia mais progressista para deter o fascismo. Porém ao adotar essa posição, os comunistas não renunciam ao objetivo final de uma revolução proletária. Tampouco a estratégia democrática não significou uma abertura no interior do partido que, nesse momento viu crescer as perseguições. Para o

\footnotetext{
${ }^{47}$ Francois Furet. Le passé d'une Illusion. Essais sur l'idée communiste au XXe siècle, Paris, Éditions Robert Laffort, 1995.

${ }^{48}$ Hobsbawm, op. cit., p. 267

49 Aurora de Chile, 1 de agosto de 1938, p. 1

$50 \mathrm{O}$ fascismo não era mais considerado como a expressão do capitalismo enquanto tal, mas segundo a célebre formula de Dimitrov no VII Congresso da Comintern em 1935, como a emanação de elementos mais reacionários, mais chauvinistas, mais imperialistas do capital financeiro. (Tradução da autora). Groppo, op. cit, p. 748.
} 
historiador Groppo os limites dessa mudança tática em defesa da democracia aparecem em 1939, quando em 23 de agosto é assinado o pacto Germano-Soviético, colocando entre parênteses o antifascismo e priorizando a luta contra o imperialismo das democracias liberais..$^{51}$

Como se dão estas tensões no Chile, entre os intelectuais antifascistas reunidos na Aliança? A princípio não podemos afirmar uma relação tão automática e direta com as diretrizes da Internacional Comunista. A própria dinâmica política interna oferece outros elementos que permitem nuançar estas relações políticas. A vitória da Frente Popular e questão do exílio aos Espanhóis permite manter a coerência no discurso antifascista exposto na revista Aurora de Chile.

A eleição de Aguirre Cerda não significou o fim das disputas políticas entre os partidos da Frente e a direita alessandrista. O Congresso tornou-se o baluarte de reação da oposição contra o novo governo, bloqueando sistematicamente suas ações ${ }^{52}$. O Partido Comunista, no entanto, manteve no ano de 1939 o apoio ao governo e conheceu nesse período um momento de crescimento da militância. Porém, segundo o historiador britânico, as relações de Aguirre Cerda com o Partido Comunista não se mantiveram incondicionais.

Se examinamos as publicações da revista da $\mathrm{AICH}$, especialmente os números posteriores ao acordo Ribbentrop-Molotov, verifica-se que foram dedicados à eleição presidencial, ao apoio da Frente Popular, e às gestões de Neruda para o auxílio aos republicanos. Não seguiram, dessa forma, de maneira tão estreita as mudanças da política da Comintern, tal como indica Groppo, que considera que o pacto germanosoviético colocava entre parênteses a política antifascista. Isso não significou que ignorassem as discussões e inflexões internacionais. Na edição de trinta de novembro de 1939, a revista Aurora de Chile publicou um extenso artigo intitulado: Nem com a Alemanha nazi, nem com as falsas democracias, da autoria de Alexey Fedia. Nele defende-se abertamente a posição da URSS e a ênfase no caráter imperialista da guerra. O autor afirma:

Em efecto tenemos necesidad de decir que el punto de vista que guiará nuestro estudio es el punto de vista de la clase obrera, tanto más cuanto que la guerra en Europa no tiene ese carácter que ha querido darsele, de lucha entre el fascismo y la democracia burguesa, sino que su función está determinada por los intereses imperialistas 53

$\mathrm{O}$ artigo tem continuidade, explicando o significado do imperialismo citando como exemplo o caso da Inglaterra e França que através do Tratado de Munique firmado em vinte e nove de setembro de 1938, permitiu a invasão da Tchecoslováquia pela Alemanha nazista.

Entretanto, apesar destas palavras indicarem a mudança de perspectiva com relação ao antifascismo, o debate na AICH continua sendo pautado por uma perspectiva das urgências nacionais. Vale lembrar que em agosto de 1939 o governo sofreu uma tentativa de golpe encabeçada pelo general Ariosto Herrera, com apoio de extremistas de direita. A ameaça opera nas fileiras da Frente Popular movimento de apoio à Aguirre Cerda, expresso nas páginas de Aurora de Chile. Por outro lado, a questão dos refugiados espanhóis ocupa os esforços e atenção dos militantes reunidos na AICH.

A Frente Popular, no entanto, se vê tomada por conflitos intrapartidários. Ainda que o Partido Comunista continuava a manter o apoio ao governo frentista, não se abstinha de críticas no sentido de exigir uma posição mais dura com relação a direita e de colocar o programa da Frente Popular em execução. ${ }^{54}$ Internacionalmente o Pacto germano-soviético exigia uma nova postura, porém o partido

\footnotetext{
51 Idem, p. 749

52Andrew Barnard. The Chilean Communist Party (1922 47), Tese defendida em 1977, Universidade de Londres 1977, p. 223.

53 Aurora de Chile, 30/11/1939.

54 Andrew Barnard. Capítulo 5. Pedro Aguirre Cerda y el Frente Popular, 1938-1941, El Partido Comunista de Chile, $1922-1947$ [en línea]. Santiago, Ariadna Ediciones, 2017. Disponible: http://books.openedition.org/ariadnaediciones/753. Consultado: 13 de marzo de 2019.
} 
adota uma estratégia de silêncio. Apesar das mudanças, o PCCH foi instruído para continuar com Frente Popular e aprofundar a luta anti-imperialista. Para o historiador Andrew Barnard:

Fueron las diferencias sobre asuntos internacionales las que provocaron la mayor tensión en las relaciones entre el Presidente y el PCCh. Antes de que se suscribiera el pacto MolotovRibbentrop, el PC, siguiendo la política exterior soviética, tuvo una disposición favorable ante las democracias de EE.UU. y Europa. Pero, luego de agosto de 1939, el comunismo criollo rápidamente descubrió que las democracias europeas eran tanto o más repugnantes que el régimen alemán. Al finalizar el año, la prensa comunista daba más espacio a la propaganda en contra de los aliados que contra Alemania. ${ }^{55}$

Nessas circunstâncias, qual foi a posição da Aliança diante das mudanças políticas nacionais? Até final de 1939, como pudemos observar, a AICH não deu muitas demonstrações de alterar profundamente a perspectiva de uma militância antifascista e em defesa da Frente Popular.

Em 1940 sua publicação oficial apenas lança dois números. Os motivos apontados são de crise financeira, porém não podemos deixar de levantar a possibilidade de conflitos políticos que paralisaram a publicação. Os dois números publicados nesse ano tomam distância dos temas políticos. O último número apesar de dedicar a capa a República espanhola, os textos são dedicados a cultura em geral com abordagens que se distanciam da militância aguerrida inicial. ${ }^{56}$

\section{Considerações finais}

É possível, a partir das considerações aqui expostas, afirmar ter sido a AICH uma entidade ativa e um braço do Partido Comunista? A bibliografia e as evidências até o momento encontradas nos permitem confirmar positivamente essa hipótese, ainda que sempre interpondo algumas nuances. Como vimos além de ter em seus quadros vários membros comunistas ocupando posições de direção na associação, suas atividades eram realizadas com a participação de membros da direção dos partidos que compunham a Frente Popular, fortalecendo o projeto de unidade. Também jornais vinculados ao partido como Frente Popular e El Siglo difundem as atividades e entrevistam os membros em diversas ocasiões. Embora a grande imprensa tentasse ignorar seus eventos, estes eram realizados em instituições importantes como a Universidade do Chile, Biblioteca Nacional, Teatro Municipal de Santiago, Teatro Caupolican e Parque Cousiño, assim como em outras sedes menores. Além destas atividades, sua adesão se expressou através da bandeira do antifascismo.

O compromisso dos intelectuais da AICH com o Partido Comunista e com a Frente Popular no Chile durante estes primeiros anos produziu e foi parte de uma cultura específica, a cultura comunista, composta por um conjunto de ideias e ações expressas e defendidas em livros, revistas, jornais e uma complexa redes de trocas nunca monolíticas. Quando falamos em apresentar algumas nuances queremos destacar a ampla e diversa composição da AICH, reforçando o sentido de uma frente unida na organização da própria entidade. Chamamos atenção também para a singularidade deste grupo formado por escritores, jornalistas, professores, músicos, etc. A ocupação que desempenham no mundo da cultura exerce peso basilar na intervenção política destes intelectuais, constituindo a própria justificativa na representação que elaboram sobre seu papel na sociedade. As listas de associados que divulgam na imprensa, indicando a posição e função dos signatários, faz-se como comprovação da legitimidade de suas palavras.

\footnotetext{
55 Idem.

56 Gerardo Seguel escreveu nesse número sobre a literatura chilena. Outro artigo discorria sobre o papel do intelectual como missioneiro da cultura, outro sobre os Selkman na Terra do Fogo. Também publicaram um texto sobre a música europeia e outro sobre a incompatibilidade entre os movimentos de reação e cultura.
} 
Como nos fala Sirinelli, ${ }^{57}$ o meio intelectual é marcado por uma engrenagem complexa que não podemos reduzir a uma reprodução automática de diretrizes sejam partidárias ou de qualquer ordem. No entanto, é forçoso apontar que foi nesse primeiro período da AICH onde melhor podemos identificar a adesão e compromisso dos intelectuais com o projeto frentista e o compartilhamento de uma cultura comunista. O afastamento de Pablo Neruda e Enrique Délano certamente dificultam a continuidade da publicação da revista Aurora de Chile. ${ }^{8}$ Nesse ano não apenas as notícias da Aliança são propagadas pelo jornal El Siglo, como nele passam a publicar escritos de membros da AICH como Gerardo Seguel e Diego Muñoz, o que nos permiti concluir que os vínculos com Partido Comunista Chileno permaneceram fortes e não se restringem à personalidade de Neruda. Com toda sua complexidade e diversidade, a experiencia da Aliança constituiu um capítulo fundamental dos movimentos políticos do século XX na América Latina e da história do engajamento dos intelectuais na luta contra o antifascista, possibilitando ainda hoje um espaço de reflexão que a historiografia mais recente tem buscado examinar como um fenômeno rico e profundamente entrelaçado na experiência social, político e cultural.

\section{Bibliografia}

AGgIO, Alberto (1999). Frente Popular, radicalismo e Revolução Passiva no Chile. São Paulo: Annablume, FAPESP.

AGUILERA, Oscar; ANTIVILO, Julia (2002). Historia de la Sociedad de Escritores de Chile: los diezprimeros años y visión general, 1931-2001. Galas Ediciones, Gobierno de Chile.

ALVAREZ, Rolando (2017). "El Partido Comunista de Chile en la década de 1930: entre 'clase contra clase' y el Frente Popular". Pacarina del Sur, n. 31, Santiago. Disponível em:

$<$ http://www.pacarinadelsur.com/home/oleajes/1474-el-partido-comunista-de-chile-en-la-decada-de1930-entre-clase-contra-clase-y-el-frente-popular>. Acesso em: 5 janeiro 2018.

BARNARD, Andrew. The Chilean Communist Party (192247). Tese defendida em 1977, Universidade de Londres.

BOBBIO, Norberto; MATTEUCCI, N; PASQUINO, G. (2010). Dicionário de Política. Brasilia: Editora UNB.

DAVID-FOX, Michael (2017). Communism and Intellectuals. In: PONS, Silvio. World Revolution and Socialism in One Country, 1917-1941. Cambridge University Press.

GREZ T. Sergio (2015). Un episodio de la política del "Tercer Período" de la Internacional Comunista: elecciones presidenciales en Chile, 1931. Historia, n. 48, vol. II, jul/dic., pp. 465-503, Santiago: Pontificia Universidad Católica de Chile.

GROPPO, Bruno (2004). El antifascismo en la cultura política comunista, in: Anuario IEHS n. 19, Buenos Aires: Universidad Nacional del Centro.

GROPPO, Bruno (2004). Fascismes, antifascismes et communismes. In: DREYFUS, M.; GROPPO, B. Les siècles des communismes. Éditions de L Atelier/Edition ouvrières, Paris, 2004.

GUASCH, Maria Victoria. Reconstrucción identitaria en el exilio político: los refugiados de la guerra civil española en Chile. Universidad Academia de Humanismo Cristiano, Escuela de Historia (Tesis de Grado), Santiago, 2011.

HOBSBAWM, Erick J. (1985). Os intelectuais e o antifascismo. In: História do marxismo, vol. 9. Rio de Janeiro: Paz e Terra.

LIRA, E. e LOVEMAN, B. (2014) Poder Judicial y conflitos políticos (Chile: 1925-1958), Santiago: Universidad Alberto Hurtado/LOM.

MILAS, Orlando. Memorias (1996). Santiago: Ed. Chile-America CESOC.

${ }^{57}$ Jean-François Sirinelli, “Os Intelectuais”, REMOND, R. Por uma História Política, Rio de Janeiro, Editora FGV, 2003 , p. 248.
${ }^{58}$ Ambos são indicados em 1940 pelo governo para ocupar funções no Consulado chileno no México. 
MILOS, Pedro (2008). La formación del Frente Popular, 1936-1938. Santiago: LOM ediciones.

MUÑOZ LAGOS, M. (1997) El poeta Gerardo Seguel. In: La prensa Austral, 1997. http://www.bibliotecanacionaldigital.cl/bnd/628/w3-article-289297.html

NERUDA, Pablo. Confieso que he vivido: Memórias. Madrid, Seix Barral, 1980.

OLIVEIRA, Angela Meirelles de (2013). Palavras como balas: imprensa e intelectuais antifascistas no Cone Sul (1933-1939). São Paulo: USP. (Tese de Doutorado)

ORY, Pascal. e SIRINELLI, Jean-François, (1986). Les Intellectuels en France, de l'Affaire Dreyfus à nos jours. Paris: Armand Colin.

SIRINELLI, Jean-François (2003). Os Intelectuais, in: REMOND, R. Por uma História Política, Rio de Janeiro: Editora FGV.

STRADA, Victorio. (1985) “Do realismo socialista ao Zdhanovismo", in: HOBSBAWM, Erick J. História do marxismo, vol. 9. Rio de Janeiro: Paz e Terra.

ULIANOVA, Olga; RIQUELME, Alfredo (2017). "Listado de publicaciones periódicas del PCCH elaborado por Raúl Barra Silva." 16/01/1938. In: Chile em los archivos Soviéticos (1922-1991). Tomo 3: Komintern y Chile 1935-1941. Santiago de Chile: DIBAM, Centro de Investigaciones Diego Barros Arana.

"Persona sugeridas por la delegación chilena para ser invitada a la Conferencia Democratica Continental." 3/02/1938. In: Chile em los arcbivos Soviéticos (19221991. Tomo 3: Komintern y Chile 1935-1941. Santiago de Chile: DIBAM, Centro de Investigaciones Diego Barros Arana.

. "Informe sobre la política de cuadros en el PC Chileno, elaborado em Moscú por Paulino González Alberdi. 7/08/1937. Chile en los archivos soviéticos 1922-1991. Tomo 3: Komintern y Chile 1935-1941. p.369. Santiago de Chile: DIBAM, Centro de Investigaciones Diego Barros Arana. 